\title{
Dopamine may preserve the myocardial oxygen balance better than dobutamine when administered with milrinone
}

\author{
[La dopamine peut mieux préserver la balance en oxygène du myocarde que la \\ dobutamine quand elle est combinée à la milrinone]
}

Isao Takamatsu MD, Fujio Karasawa MD PhD, Tomohiro Okuda MD

Purpose: To compare the hemodynamic effects of dopamine with those of dobutamine when administered with milrinone in patients undergoing non-cardiac surgery.

Methods: In 14 patients undergoing major surgery during anesthesia with isoflurane, milrinone $\left(50 \mu \mathrm{g}^{\mathrm{kg}} \mathrm{g}^{-1}\right.$ followed by 0.25 $\mu \mathrm{g} \cdot \mathrm{kg}^{-1} \cdot \mathrm{min}^{-1}$ ) was administered. Hemodynamic baseline values were assessed 50 min after continuous infusion of milrinone. Additional infusion of either dopamine or dobutamine, randomly selected, was started at the rate of 4 and later $8 \mu \mathrm{g} \cdot \mathrm{kg}^{-1} \cdot \mathrm{min}^{-1}$; each hemodynamic variable was measured 20 min after changing the infusion rate. One hour after ceasing the infusion of one catecholamine (dopamine or dobutamine), the other was infused at the rate of 4 and $8 \mu \mathrm{g} \cdot \mathrm{kg}^{-1} \cdot \mathrm{min}^{-1}$.

Results: Milrinone increased heart rate $(H R)$, but decreased mean arterial pressure (MAP) and systemic vascular resistance (SVR) $(P<$ 0.05 for each). Dopamine administered with milrinone significantly increased MAP and cardiac output (CO), whereas dobutamine significantly increased $\mathrm{HR}$ and $\mathrm{CO}$, but decreased SVR. By comparison between dopamine and dobutamine administered at the rate of $8 \mu \mathrm{g} \cdot \mathrm{kg}^{-1} \cdot \mathrm{min}^{-1}$, there was a significant difference in HR, MAP, and SVR $(P<0.01,0.01$, and 0.05, respectively).

Conclusion: Dopamine and dobutamine administered with milrinone induce different hemodynamic changes: dopamine increases MAP without affecting $H R$, whereas dobutamine increases $H R$. Our data suggest that the myocardial oxygen balance might be better preserved with dopamine than with dobutamine when administered with milrinone.

Objectif : Comparer les effets hémodynamiques de la dopamine à ceux de la dobutamine quand elles sont administrées avec de la milrinone pour une intervention non cardiaque.
Méthode: Chez 14 patients devant subir une importante intervention chirurgicale pendant une anesthésie avec de l'isoflurane, de la milrinone $\left(50 \mu \mathrm{g} \cdot \mathrm{kg}^{-1}\right.$ suivis de $\left.0,25 \mu \mathrm{g} \cdot \mathrm{kg}^{-1} \cdot \mathrm{min}^{-1}\right)$ a été administrée. Les valeurs hémodynamiques de base ont été enregistrées 50 min après la perfusion continue de milrinone. Une perfusion complémentaire de dopamine ou de dobutamine, choisie au hasard, a été donnée selon un débit de 4 et plus tard de $8 \mu \mathrm{g} \cdot \mathrm{kg}^{-1} \cdot \mathrm{min}^{-1}$; chaque variable hémodynamique a été mesurée 20 min après le changement de débit. Une heure après la fin de la perfusion d'une des catécholamines (dopamine ou dobutamine), l'autre a été perfusée à 4 et $8 \mu \mathrm{g} \cdot \mathrm{kg}^{-1} \cdot \mathrm{min}^{-1}$.

Résultats : La milrinone a augmenté la fréquence cardiaque (FC), mais diminué la tension artérielle moyenne (TAM) et la résistance vasculaire systémique (RVS) $(P<0,05$ pour chacune). La dopamine administrée avec la milrinone a fait augmenter la TAM et le débit cardiaque (DC) de manière significative tandis que la dobutamine a fait augmenter significativement la FC et le DC, mais diminuer la RVS. Si on compare la dopamine et la dobutamine administrées à 8 $\mu \mathrm{g} \cdot \mathrm{kg}^{-1} \cdot \mathrm{min}^{-1}$, il y a une différence significative de FC, TAM et RVS (P $<0,01,0,01$, et 0,05 , respectivement).

Conclusion : La dopamine et la dobutamine combinées à la milrinone induisent des changements hémodynamiques différents : la dopamine augmente la TAM sans modifier la FC, tandis que la dobutamine augmente la FC. La balance en oxygène du myocarde serait donc mieux préservée avec la dopamine, comparée à la dobutamine, quand elle est combinée à la milrinone.

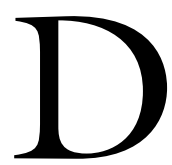

OPAMINE and dobutamine are traditionally used in heart failure to improve cardiac function, but their use is limited by a possible increase in myocardial $\mathrm{O}_{2}$ consumption $\left(\mathrm{MVO}_{2}\right)$ and the development of tolerance. ${ }^{1,2}$ Milrinone, one of the phosphodiesterase-III inhibitors,

From the Department of Anesthesiology, National Defense Medical College, Tokorozawa, Saitama, Japan.

Address correspondence to: Dr. F. Karasawa, Department of Anesthesiology, National Defense Medical College, Namiki 3-2,

Tokorozawa, Saitama 359-8513, Japan. Phone: +81-42-995-1692; Fax: +81-42-992-1215; E-mail: karasawa@me.ndmc.ac.jp 
improves cardiac function without increasing myocardial oxygen consumption ${ }^{3-7}$ and the development of tolerance. ${ }^{8}$ Furthermore, combined administration of dobutamine and milrinone has been recommended to induce beneficial additive effects in heart failure. ${ }^{9}$ However, combined administration of dobutamine and milrinone reduces mean arterial pressure (MAP) and increases heart rate (HR) ${ }^{10}$ which can cause myocardial ischemia in patients with coronary artery disease. Conversely, norepinephrine combined with amrinone is effective for maintaining systemic blood pressure during aortocoronary graft surgery. ${ }^{11}$

Dopamine stimulates dopaminergic receptors at low doses, and at somewhat higher doses, exerts a positive inotropic effect on the myocardium through $\beta_{1}$-adrenergic receptors, but tachycardia is less prominent during infusion of dopamine than of isoproterenol. ${ }^{12,13}$ At high doses, dopamine activates vascular $\alpha_{1}$-adrenergic receptors, leading to vasoconstriction. ${ }^{13}$ Therefore, dopamine might also be beneficial for maintaining blood pressure during infusion of phosphodiesteraseIII inhibitors. Although there are a few reports assessing combination therapy with dobutamine and milrinone, ${ }^{9}$ the hemodynamic effect of combination therapy with dopamine and milrinone is poorly documented. In the present study, the hemodynamic effects of dopamine were compared with those of dobutamine when administered with milrinone in 14 patients during anesthesia.

\section{Patients and methods}

The study was approved by the Ethics Committee of the National Defense Medical College. Sixteen patients (ASA physical status I to III; nine men and seven women) undergoing elective surgery for carcinoma of the liver, bile duct, or pancreas were enrolled in the study. None of the patients had a history of cardiac disease or preoperative electrocardiogram, chest $x$-ray, or ultrasonic cardiograph abnormalities. Written informed consent was obtained from all patients. The patients were premedicated with atropine $(0.5 \mathrm{mg})$ and hydroxyzine $(50 \mathrm{mg})$ intramuscularly $30 \mathrm{~min}$ before the start of anesthesia. Before inducing anesthesia, an epidural catheter was inserted, and $1.5 \%$ mepivacaine was administered through the catheter to avoid nociceptive stimulation at skin incision; however, additional mepivacaine was not used before the end of the study. Anesthesia was induced with propofol $\left(1.0-2.0 \mathrm{mg} \cdot \mathrm{kg}^{-1}\right)$ and vecuronium bromide $\left(0.1 \mathrm{mg} \cdot \mathrm{kg}^{-1}\right)$, and the trachea was intubated. The lungs were ventilated mechanically and anesthesia was maintained with $3 \mathrm{~L} \cdot \mathrm{min}^{-1}$ nitrous oxide and $3 \mathrm{~L} \cdot \mathrm{min}^{-1}$ oxygen supplemented with isoflu- rane $(0.8$ to $1.5 \%)$, the concentration of which was not altered during the study. Acetate Ringer's solution was infused at the rate of approximately 10 $\mathrm{mL} \cdot \mathrm{kg}^{-1} \cdot \mathrm{hr}^{-1}$, but additional colloidal solution was not given during the investigation. After induction of anesthesia, a pulmonary arterial catheter was introduced via the right internal jugular vein. HR, MAP and systolic arterial pressure (SAP), central venous pressure (CVP), CO, and pulmonary capillary wedge pressure (PCWP) were measured.

When hemodynamics had stabilized after the start of the surgical procedure, hemodynamic values were measured as baseline values before administration of milrinone. Milrinone $\left(50 \mu \mathrm{g} \cdot \mathrm{kg}^{-1}\right)$ was then injected over ten minutes as a loading dose, followed by a continuous infusion of $0.25 \mu \mathrm{g} \cdot \mathrm{kg}^{-1} \cdot \mathrm{min}^{-1}$. Hemodynamic values were measured again 50 min after the continuous infusion of milrinone (Mil-1). Additional infusion of either dopamine or dobutamine was started at the rate of $4 \mu \mathrm{g} \cdot \mathrm{kg}^{-1} \cdot \mathrm{min}^{-1}$. Using a random shuffle, dopamine or dobutamine was selected for infusion and blinded to the anesthesiologist. A second dose $(8$ $\mu \mathrm{g} \cdot \mathrm{kg}^{-1} \cdot \mathrm{min}^{-1}$ ) of dopamine (or dobutamine) was also infused. Each hemodynamic variable was measured 20 min after changing the infusion rate. One hour after ceasing the infusion of either catecholamine (dopamine or dobutamine), when the hemodynamics had returned to baseline values (Mil-2), the other drug was infused at the rate of $4 \mu \mathrm{g} \cdot \mathrm{kg}^{-1} \cdot \mathrm{min}^{-1}$ and later at 8 $\mu \mathrm{g} \cdot \mathrm{kg}^{-1} \cdot \mathrm{min}^{-1}$. Changes in the systemic vascular resistance (SVR), rate pressure product (RPP: HR.SAP), and pressure rate quotient (PRQ: MAP.HR $\mathrm{HR}^{-1}$ ) were also assessed to compare the effect of dopamine and dobutamine administered with milrinone.

\section{Statistical analysis}

Data are presented as number of patients or mean \pm standard deviation (SD). Two-way analysis of variance (ANOVA) for repeated measurements was used to assess changes between groups and one-way ANOVA was used to compare raw data over time within groups. Post hoc analysis to allow for multiple comparisons was performed using a Bonferroni/Dunn correction. Student's t test was used to make single comparisons. Proportional data were evaluated using the Chi square test. A $P$ value of less than 0.05 was considered statistically significant.

\section{Results}

Patient characteristics are summarized in Table I. Data of two patients whose sequence of infusion was dobutamine followed by dopamine were discarded because the surgical procedures ended before completion of 
TABLE I Patient characteristics.

\begin{tabular}{ll}
\hline Age $(\mathrm{yr})$ & $59 \pm 11$ \\
Gender $(\mathrm{M} / \mathrm{F})$ & $9 / 5$ \\
Height $(\mathrm{cm})$ & $161 \pm 10$ \\
Weight $(\mathrm{kg})$ & $56 \pm 12$ \\
The sequence of infusion & \\
Dopamine followed by dobutamine & 8 \\
Dobutamine followed by dopamine & 6 \\
\hline
\end{tabular}

Data are expressed as number of patients or mean \pm SD.

TABLE II Hemodynamic effects of milrinone

\begin{tabular}{lllllll}
\hline & $H R$ & MAP & CVP & $C O$ & PCWP & SVR \\
\hline Pre & $88 \pm 18$ & $74 \pm 11$ & $7 \pm 2$ & $6 \pm 2$ & $9 \pm 3$ & $1019 \pm 422$ \\
Mil-1 & $97 \pm 16^{*}$ & $68 \pm 9^{*}$ & $6 \pm 2^{*}$ & $7 \pm 2^{*}$ & $6 \pm 3^{*}$ & $804 \pm 291^{*}$ \\
Mil-2 & $97 \pm 18^{*}$ & $67 \pm 7^{*}$ & $6 \pm 2$ & $6 \pm 2$ & $6 \pm 4^{*}$ & $828 \pm 241^{*}$ \\
\hline
\end{tabular}

Data are expressed as mean \pm SD. Pre denotes hemodynamic values before administration of milrinone. The hemodynamic values were obtained $50 \mathrm{~min}$ after continuous infusion of milrinone (Mil1). The second data obtained after ceasing administration of the first catecholamine (dopamine or dobutamine) are expressed as Mil-2. $\mathrm{HR}=$ heart rate, $\mathrm{MAP}=$ mean arterial pressure, $\mathrm{CVP}=$ central venous pressure, $\mathrm{CO}=$ cardiac output, $\mathrm{PCWP}=$ pulmonary capillary wedge pressure, SVR = systemic vascular resistance. ${ }^{*} P<0.05$ vs Pre .

the study. Changes in hemodynamics after infusion of milrinone are shown in Table II. There was no significant difference between hemodynamic values measured after ceasing administration of the first and second catecholamine (Mil-1 and Mil-2, respectively).

There was no significant difference in any hemodynamic baseline value between the dopamine and dobutamine groups (Figure). Increasing the dose of dopamine to $8 \mu \mathrm{g} \cdot \mathrm{kg}^{-1} \cdot \mathrm{min}^{-1}$ did not change $\mathrm{HR}$, MPAP CVP, or PCWP, but increased MAP and CO $(P<0.001$ by ANOVA $)$ for each when administered with milrinone. Dobutamine administered with milrinone significantly increased HR $(P<0.0001$ by ANOVA). Dobutamine at the rate of 4 , but not 8 $\mu \mathrm{g} \cdot \mathrm{kg}^{-1} \cdot \mathrm{min}^{-1}$ slightly increased MAP $(P<0.05)$ but CVP was not significantly affected by dobutamine. Although dobutamine slightly decreased PCWP $(P<$ 0.05 ), it significantly increased CO.

The HR following administration of 8 $\mu \mathrm{g} \cdot \mathrm{kg}^{-1} \cdot \mathrm{min}^{-1}$ dobutamine was higher than that following administration of $8 \mu \mathrm{g} \cdot \mathrm{kg}^{-1} \cdot \mathrm{min}^{-1}$ dopamine $(P$ $<0.01$, Figure A). MAP and SVR following administration of $8 \mu \mathrm{g} \cdot \mathrm{kg}^{-1} \cdot \mathrm{min}^{-1}$ dobutamine were lower than that following administration of $8 \mu \mathrm{g} \cdot \mathrm{kg}^{-1} \cdot \mathrm{min}^{-1}$ dopamine $(P<0.01$, Figure B; $P<0.05$, Figure $\mathrm{F})$.
Increasing the dose of dopamine and dobutamine significantly increased the RPP (Figure G); however, there was no significant difference between the two groups. The PRQ increased with increasing doses of dopamine, whereas it decreased with increasing doses of dobutamine (Figure $\mathrm{H}$ ).

\section{Discussion}

In the present study, dopamine administered with milrinone increased MAP and $\mathrm{CO}$ but did not change HR, CVP, PCWP, and SVR. On the other hand, dobutamine administered with milrinone increased HR and CO, but decreased PCWP and SVR. In patients with heart failure, ${ }^{9,10}$ the combination of milrinone and dobutamine causes an increase in HR and a fall in PCWP and SVR, which is consistent with our results. During weaning from cardiopulmonary bypass, ${ }^{11}$ amrinone combined with norepinephrine maintains an adequate blood pressure. Because a higher dose of dopamine induces vasoconstriction through activating vascular $\alpha_{1}$-adrenergic receptors, ${ }^{13}$ it is not unexpected that compared with two afterload reducers given simultaneously (milrinone + dobutamine), the combination of an afterload reducer and enhancer (milrinone and dopamine particularly in $\alpha$-range) may work better, because of an unacceptable low blood pressure with the former combination. However, the comparative effects of dopamine and dobutamine in combination with phosphodiesterase-III inhibitors remained unclear. Our results show that dopamine and dobutamine administered with milrinone have different effects on HR, MAP, and SVR: dopamine increases MAP without affecting HR, whereas dobutamine increases HR.

Inotropic agents (e.g., ß-adrenergic receptor agonists, phosphodiesterase inhibitors) administered to patients with congestive heart failure increase $\mathrm{MVO}_{2}$, and may provoke myocardial ischemia, especially in patients with coronary artery disease. Although the combined administration of dobutamine and milrinone may induce beneficial additive effects in severe heart failure, ${ }^{9}$ dobutamine infused with milrinone might worsen the myocardial oxygen balance because this combination increases $\mathrm{HR}$, a major determinant of $\mathrm{O}_{2}$ consumption. Our results with combined infusion of dobutamine and milrinone are similar to those from studies with hydralazine, which reduces afterload but induces tachycardia, provoking myocardial ischemic events in severe chronic heart failure. ${ }^{14}$ Taken together, the combination regimen of dobutamine and milrinone might decrease myocardial oxygenation.

Dopamine combined with milrinone did not change HR from baseline in the present study. 

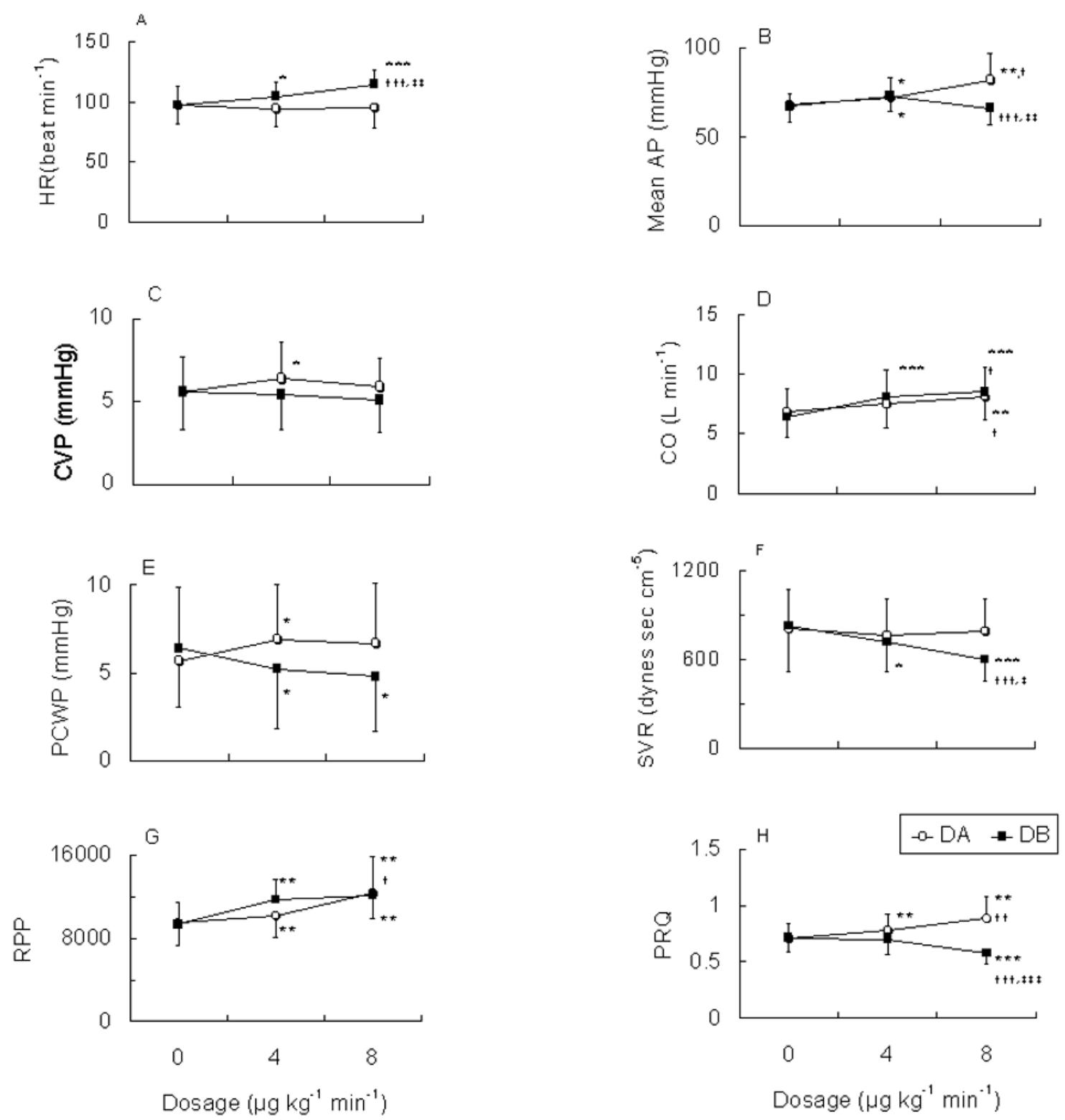

FIGURE Changes in hemodynamic variables during infusion of dopamine or dobutamine combined with milrinone. HR = heart rate; Mean $\mathrm{AP}=$ mean arterial pressure $\mathrm{CVP}=$ central venous pressure $; \mathrm{CO}=$ cardiac output; $\mathrm{PCWP}=$ pulmonary capillary wedge pressure; SVR = systemic vascular resistance; $\mathrm{RPP}=$ rate pressure product; $\mathrm{PRQ}=$ pressure rate quotient.

${ }^{*},{ }^{* *}$, or ${ }^{* *} P<0.05 .0 .01$, or 0.001 , respectively, vs values without catecholamine infusion in the same group (paired t test). ${ }^{t}, \mathrm{tt}$, or ${ }^{t+t} P$ $<0.05,0.01$, or 0.001 , respectively, vs values at the rate of $4 \mu \mathrm{g} \cdot \mathrm{kg}^{-1} \cdot \mathrm{min}^{-1}$ in the same group (paired t test). ${ }^{\ddagger} \neq \neq \neq$, or ${ }^{\ddagger \ddagger \ddagger} P<0.05,0.01$, or 0.001 , respectively, $v s$ the corresponding value in the dopamine group.

Because the combination increased MAP, an increase in HR might have been suppressed via the baro-reflex. Dopamine might also be effective for the treatment of hypotension caused by phosphodiesterase inhibitors, because higher doses of dopamine increase blood pressure. However, our results are limited to non-car- diac patients. Further studies are needed to elucidate the efficacy of this combination in patients with coronary artery disease.

There was no significant difference in RPP, an index of $\mathrm{MVO}_{2}{ }^{15,16}$ between dopamine and dobutamine in the present study. On the other hand, the 
PRQ characterized hemodynamic differences between dopamine and dobutamine administered with milrinone. Despite the preliminary report by Shiraki et al. that a PRQ of less than 1 is associated with myocardial ischemia, ${ }^{17}$ the use of PRQ as a predictor of myocardial ischemia is limited, especially when its value is less than $1 .{ }^{18,19}$

In conclusion, when administered with milrinone under anesthesia with isoflurane, dopamine increases $\mathrm{MAP}$ and $\mathrm{CO}$ without changing $\mathrm{HR}$, whereas dobutamine increases $\mathrm{HR}$ and $\mathrm{CO}$. Our results suggest that dopamine preserves the myocardial oxygen balance better than dobutamine when administered with milrinone.

\section{References}

1 Leier CV, Heban PT, Huss P, Bush CA, Lewis RP. Comparative systemic and regional hemodynamic effects of dopamine and dobutamine in patients with cardiomyopathic heart failure. Circulation 1978; 58: 466-75.

2 Liggett $S B$. Desensitization of the $\beta$-adrenergic receptor: distinct molecular determinants of phosphorylation by specific kinases. Pharmacol Res 1991; 24(Suppl): $29-41$.

3 Monrad ES, Mckay RG, Baim DS, et al. Improvement in indexes of diastolic performance in patients with congestive heart failure treated with milrinone. Circulation 1984; 70: 1030-7.

4 Monrad ES, Baim DS, Smith HS, Lanoue A, Brannwald $E$, Grossman W. Effects of milrinone on coronary hemodynamics and myocardial energetics in patients with congestive heart failure. Circulation 1985; 71: 972-9.

5 Dubois-Rande JL, Duval-Moulin AM, Saal JP, et al. Physiologic assessment of milrinone therapy in severe heart failure patients. J Cardiovasc Pharmacol 1991; 17: 941-8.

6 Klocke RK, Mager G, Kux A, Hopp HW, Hilger HH. Effects of a twenty-four-hour milrinone infusion in patients with severe heart failure and cardiogenic shock as a function of the hemodynamic initial condition. Am Heart J 1991; 121: 1965-73.

7 Mitrovic V, Stohring R, Schlepper M. The use of intravenous milrinone in chronic symptomatic ischemic heart disease. Am Heart J 1991; 121: 1983-94.

8 Shipley JB, Tolman D, Hastillo A, Hess ML. Milrinone: basic and clinical pharmacology and acute and chronic management. Am J Med Sci 1996; 311: 286-91.

9 Meissner A, Herrmann G, Gerdesmeyer L, Simon R. Additive effects of milrinone and dobutamine in severe heart failure (German). Z Kardiol 1992; 81: 266-71.

10 Grose R, Strain J, Greenberg M, LeJemtel TH. Systemic and coronary effects of intravenous milrinone and dobutamine in congestive heart failure. J Am Coll Cardiol 1986; 7: 1107-13.

11 Hardy JF, Searle N, Roy M, Perrault J. Amrinone, in combination with norepinephrine, is an effective firstline drug for difficult separation from cardiopulmonary bypass. Can J Anaesth 1993; 40: 495-501.

12 Yeh BK, McNay JL, Goldberg LI. Attenuation of dopamine renal and mesenteric vasodilation by haloperidol: evidence for a specific dopamine receptor. J Pharmacol Exp Ther 1969; 168: 303-9.

13 Hoffman BB, Lfkowitz RJ. Catecholamines, sympathomimetic drugs, and adrenergic receptor antagonists. In: Hardmann JG, Limbird LE, Molinoff PB, Ruddon RW (Eds.). Goodman \& Gilman's The pharmacological Basis of Therapeutics, $9^{\text {th }}$ ed. Tokyo, Japan: McGraw-Hill, 1996: 211-2.

14 Packer M, Meller J, Medina N, Yushak M, Gorlin R. Provocation of myocardial ischemic events during initiation of vasodilator therapy for severe chronic heart failure. Clinical and hemodynamic evaluation of 52 consecutive patients with ischemic cardiomyopathy. Am J Cardiol 1981; 48: 939-46.

15 Lieberman RW, Orkin FK, Jobes DR, Schwartz AJ. Hemodynamic predictors of myocardial ischemia during halothane anesthesia for coronary-artery revascularization. Anesthesiology 1983; 59: 36-41.

16 Wilkinson PL, Moyers JR, Ports T, Chatterjee K, Ullyott $D$, Hamilton WK. Rate-pressure product and myocardial oxygen consumption during surgery for coronary artery bypass. Circulation 1979; 60: 170-3.

17 Shiraki H, Lee S, Hong $\Upsilon W$, et al. Diagnosis of myocardial ischemia by the pressure-rate quotient and diastolic time interval during coronary artery bypass surgery. J Cardiothorac Anesth 1989; 3: 592-6.

18 Gordon MA, Urban MK, O'Connor T, Barash PG. Is the pressure rate quotient a predictor or indicator of myocardial ischemia as measured by ST-segment changes in patients undergoing coronary artery bypass surgery? Anesthesiology 1991; 74: 848-53.

19 Harris SN, Gordon MA, Urban MK, O'Connor TZ, Barash $P G$. The pressure rate quotient is not an indicator of myocardial ischemia in humans. An echocardiographic evaluation. Anesthesiology 1993; 78: 242-50. 